\title{
Phospholipids vs. neutral lipids: Effects on digestive enzymes in Atlantic cod (Gadus morhua) larvae
}

\author{
Per-Arvid Wold ${ }^{a,}{ }^{*}$, Katja Hoehne-Reitan ${ }^{a}$, Chantal L. Cahu ${ }^{b}$, Jose Zambonino Infante ${ }^{b}$, Jose \\ Rainuzzo ${ }^{c}$ and Elin Kjørsvik ${ }^{\mathrm{a}}$
}

\author{
aThe Norwegian University of Science and Technology, Department of Biology, N-7491 Trondheim, Norway \\ bUMR 1067 of Fish Nutrition, IFREMER BP 70, 29280 Plouzané, France \\ ${ }^{\mathrm{c}} \mathrm{SINTEF}$ Fisheries and Aquaculture, N-7465 Trondheim, Norway
}

*: Corresponding author : Per-Arvid Wold, email address : per-arvid.wold@bio.ntnu.no

\begin{abstract}
:
The aim of this study was to evaluate the effect of dietary lipid classes (phospholipid vs. neutral lipid) and level of n-3 highly unsaturated fatty acids (HUFAs) on growth, survival and digestive enzymatic activity in Atlantic cod (Gadus morhua) larvae. Larvae were fed enriched rotifers from mouth opening and were weaned to formulated diets during a co-feeding period lasting from 17 days post hatch (dph) to $24 \mathrm{dph}$. Larvae were fed exclusively compound diets from $24 \mathrm{dph}$ until the end of the experiment. Three isoproteic and isolipidic compound diets with gradually decreasing levels of DHA and EPA in the dietary phospholipid fraction (diet PL3 > PL1 > NL1) and increasing levels of total dietary neutral lipids (PL3 < PL1 < NL1) were used. Larvae fed the PL3 or PL1 had a significant higher dry weight than larvae fed the NL1 diet at the end of the experiment (45 dph). Survival did not differ significantly between treatments. A gut maturation index based on the relation between the amount of the brush border enzyme alkaline phosphatase and the cytosolic enzyme leucine-alanine aminopeptidase showed that the enterocyte maturation on 35 and 45 dph was better in larvae fed the PL3 and PL1 diet than larvae fed the NL1 diet. Dietary composition did not significantly affect the activity of $\alpha$-amylase, but an age specific decrease in activity was observed. The dietary composition did affect the specific activity of trypsin, although showing variation in pattern between different larval ages at sampling. The activity of neutral lipase showed high variability between dietary treatments, but at the end of the experiment the specific activity of neutral lipase was positively connected to the dietary neutral lipid levels. The results from this study showed that cod larvae use DHA and EPA in the phospholipid fraction more efficiently compared to those in the neutral lipid fraction.
\end{abstract}

Keywords: Atlantic cod larvae; Early weaning; Phospholipids; Digestive enzymes; Gut maturation

\section{Introduction}

The commercial juvenile production of Atlantic cod (Gadus morhua) is still a challenge, much due to suboptimal nutrition during the first stages. Cod larval rearing is still largely 
depending on a live feed period with rotifers (Brachionus sp.) and Artemia during the early larval phase. The nutritional value of these commonly used live feed organisms is variable, and in particular the Artemia lipid composition after enrichment is rather unstable (Olsen et al., 2004). Due to high costs in live feed production, one main objective in cod larval rearing is to formulate a compound diet that can substitute live prey, in particular Artemia, as early as possible during larval development. Cahu et al., (2003a) demonstrated that complete substitution of live feed by formulated diets 51 in marine fish larval rearing is possible when larval sea bass (Dicentrarchus labrax) were reared only with compound diets from mouth opening. So far this is not achieved with cod larvae and cod larvae fed formulated diets before development of the stomach have shown less growth than larvae fed rotifers and Artemia (MacQueen Leifson, 2003). A shift from rotifers to Artemia or to a formulated diet 20-30 dph is usual in cod aquaculture industry (Hamre, 2006). Baskerville-Bridges and Kling (2000) and MacQueen Leifsson (2003) demonstrated that cod larvae can be weaned directly from rotifers to a specialized microparticulate diet without incorporating an intermediate Artemia phase, although growth was poorer than in larvae fed Artemia. The present study is one of few earlyweaning experiments performed with cod larvae where Artemia is entirely substituted by formulated diets as early as 17 days post hatching (dph) to investigate the effect of dietary lipid composition on larval growth and development. During the last two decades ontogeny of digestive enzymes and developmental features of the digestive tract have been well documented in several species (Zambonino Infante and Cahu, 2001; Kjørsvik et al., 2004). The development of pancreatic enzymes follows a genetically programmed pattern which is subtly modified by the diet composition (Cahu and Zambonino Infante, 2001; Hoehne-Reitan and Kjørsvik, 2004). All digestive enzymes, except the stomach enzymes, seem to be present in pelagic marine fish larvae during the first period of feeding (Kjørsvik et al. 2004). This indicates that marine fish larvae are capable of digesting formulated diets from the beginning of start feeding. Recent work has described the activity of several key enzymes throughout the ontogeny of larvae cod (Perez-Casanova et al., 2006) in order to investigate the development of cod larval digestive capacity. The authors concluded that cod larvae are capable of digesting lipids, as also reported by Hoehne (1999) and protein at the time of mouth opening and that they have a limited capacity to digest 
carbohydrates. So far the dietary effects on digestive enzyme activity in cod larvae have not been shown.

Dietary lipids are the main source of energy for developing fish larvae (Sargent et al., 2002), and the n-3 highly unsaturated fatty acids (HUFA) have been identified as essential dietary components for marine fish since they cannot synthesize them de novo (Cahu and Zambonino Infante, 2001; Bell et al., 2003). The optimal fatty acid composition and lipid levels for cod larvae are not known. Generally, marine fish larvae require large amounts of docosahexaenoic acid (DHA, 22:6n-3) and eicosapentaenoic acid (EPA, 20:5n-3) (Rainuzzo et al., 1997; Sargent et al., 2002; Izquierdo, 2004) and the optimal level of EPA+ DHA in marine finfish larvae seem to be about 3\% of dietary dry matter (Cahu and Zambonino Infante, 2001; Sargent et al., 2002). The use of diets with a high DHA/EPA ratio (>1.5 - 2.0) generally shows better larval survival and growth than a lower DHA/EPA ratio (Kjørsvik et al., 2004). Marine phospholipids (PLs) are carriers of HUFAs and are considered as good lipid sources for starter feeds for marine fish larvae (Sargent et al., 2002). Marine fish larvae possess a high capacity to utilize phospholipids (Geurden et al., 1998; Salhi et al., 1999; Izquierdo et al., 2001) and micro diets containing more marine phospholipids than marine triacylglyceroles (TAG) resulted in better growth in larval sea bass (Cahu et al., 2003a; Gisbert et al., 2005). It is recommended that marine fish larvae are given $10 \%$ marine phospholipids of dietary dry matter (Sargent et al., 2002; Cahu et al., 2003b).

The aim of the present study was to evaluate the effects of dietary incorporation of n-3 HUFA in different lipid classes (phospholipids vs. neutral lipids) and the level of n-3 HUFA in formulated diets on growth, survival and activity of some digestive enzymes in early weaned cod larvae. Growth, survival and specific activity of pancreatic- and intestinal digestive 
101

102

103

104

105

106

107

108

109

110

111

112

113

114

115

116

117

118

119

120

121

122

123

124

125

enzymes were followed. The experimental design was based on isolipidic and isoproteic microdiets from 17 until 45 dph.

\section{Material and methods}

\subsection{Experimental design}

Atlantic cod eggs were obtained from Troms Marine Yngel A/S (Tromsø, Norway) two days before hatching. Eggs were disinfected in glutaraldehyde in seawater (0.4g/l) for $10 \mathrm{~min}$ (Salvesen and Vadstein, 1995) and incubated at a stocking density of 150 eggs/l in nine $160 \mathrm{l}$ cone bottomed black tanks in darkness at $7.5^{\circ} \mathrm{C}$ (salinity $34 \%$ ). Each dietary treatment was run in three replicate tanks.

After hatching, light was turned on (24h) and the temperature was gradually increased from 8 to $12^{\circ} \mathrm{C}$ between 1 and $6 \mathrm{dph}$, and then kept constant at $12^{\circ} \mathrm{C} \pm 0.2^{\circ} \mathrm{C}$. Water exchange was gradually increased from $0.1 \mathrm{l} / \mathrm{min}$ at hatching to $0.9 \mathrm{l} / \mathrm{min}$ from $30 \mathrm{dph}$. Larval rearing lasted up to $45 \mathrm{dph}$. Dead larvae were removed every second day from 1-17 dph and were removed and counted every day from 17 dph onwards.

\subsection{Live feed enrichment and larval feeding}

The larvae were fed rotifers (Brachionus. "Nevada” within the Brachionus plicatilis cryptic species complex, Gomez et al., 2002), long-term enriched with the marine emulsion Marol E provided by SINTEF Fisheries and Aquaculture (Trondheim, Norway). Cod larvae were fed rotifers three times every day from 3 dph. Feed density was 3000-5000 ind/l until 4 dph, and then increased to 5000-7000 ind/l from 5 dph. Algal paste (Nannochloropsis, Reed mariculture, USA) was added 1-3 times a day from 2 dph until the end of the rotifer phase in a 
126

127

128

129

130

131

132

133

134

135

136

137

138

139

140

141

142

143

144

145

146

147

148

149

150

concentration of $2 \mathrm{mg} \mathrm{C/l}$. From 17 to 24 dph there was an overlap between rotifers and formulated diets, and the amounts of rotifers were gradually reduced. From $24 \mathrm{dph}$ cod larvae were fed formulated diets exclusively.

Small amounts of the experimental formulated diets were fed manually to the larvae $(0.15 \mathrm{~g} \mathrm{x}$ 10) on day 17 to start weaning. On $18 \mathrm{dph}$, 3g/day of formulated diets were added using continuous automatic belt feeders, gradually increasing the amount of feed added per day to each tank to $10 \mathrm{~g}$ from $31 \mathrm{dph}$. A pellet size of $<200 \mu \mathrm{m}$ was used from 17 to $30 \mathrm{dph}$ with an increase to $200-400 \mu \mathrm{m}$ from $30 \mathrm{dph}$. An overlap using a mixture of both pellets sizes was conducted from 30 to $36 \mathrm{dph}$.

\subsection{Formulated diets}

Three isoproteinic and isolipidic diets which varied in their lipid class composition, PL vs. NL, were used (Table 1). The lipid composition differed by the amount of cod liver oil, marine lecithin and soybean lecithin added. PL3 and PL1 comprised a mixture of marine and soybean lecithin as only source of lipids. The phospholipids were incorporated in two different levels and in inverse relationship into the two different diets. NL1 contained only soybean lecithin as the PL source and marine TAG (cod liver oil). These differences gave a proximate composition with gradually decreasing levels of DHA and EPA in the dietary phospholipid fraction (PL3 $>$ PL1 $>$ NL1) and increasing of total dietary neutral lipid levels (PL3 $<$ PL1 $<$ NL1) (Table 1).

All diets contained 51\% defatted fish meal and 14\% hydrolyzed fish meal (CPSP), 8\% vitamin mixture, $4 \%$ mineral mixture and $2 \%$ of betaine. The total lipid content in all diets was 21\%. The diets were manufactured by UMR 1067 of Fish Nutrition, IFREMER (France) according to Gisbert et al. (2005). 
151

152

153

154

155

156

157

158

159

160

161

162

163

164

165

166

167

168

169

170

171

172

173

174

175

\subsection{Sampling}

All larvae were anaesthetised with Metacainum (Tamro 257675) and rinsed in distilled water before further treatment. Larvae collected for enzyme assays were immediately frozen in liquid nitrogen and stored at $-80^{\circ} \mathrm{C}$. Larvae sampled to monitor growth were collected individually in tin capsules and dried for 48 hours at $60^{\circ} \mathrm{C}$ for dry weight (DW).

\subsection{Growth and survival}

On 1 dph 15 larvae were sampled randomly from all tanks, and on 10, 17, 24, 35 and 45 dph, 15 larvae were sampled from each tank.

The larval specific growth rate (SGR, \%/days) was calculated according to Kjørsvik et al. (2004):

$$
\mathrm{SGR}=\ln \left(\mathrm{W}_{\mathrm{t}} / \mathrm{W}_{0}\right) / \mathrm{t} \quad(\text { equation } 1)
$$

$\mathrm{W}_{0}$ is the initial individual dry weight and $\mathrm{W}_{\mathrm{t}}$ is the individual dry weight at time $\mathrm{t}$.

The daily weight increase (DWI in \%) was calculated from the specific growth rate according to Kjørsvik et al. (2004):

$$
\left.\% \mathrm{SGR}=\left(\mathrm{e}^{\mathrm{SGR}}-1\right) \times 100 \quad \text { (equation } 2\right)
$$

Larval survival was calculated by daily counting of dead larvae from $17 \mathrm{dph}$, and by counting remaining larvae at the end of the experiment. Numbers were corrected for sampled larvae.

2.6 Spectrophotometric determination of trypsin, $\alpha$-amylase, alkaline phosphatase (AP) and leucin-alanin aminopeptidase (leu-ala) specific activity

Before the introduction of the microdiets on $17 \mathrm{dph}, 90$ larvae were sampled and pooled from all tanks. Larvae were sampled separately from each tank on 24 dph (n = 50/tank), 35 dph (n 
$176=30 / \operatorname{tank})$ and $45 \mathrm{dph}(\mathrm{n}=30 /$ tank). In order to determine enzymatic activities in specific

177 segments, larvae older than 24 days were dissected after thawing as described by Cahu and

178 Zambonino Infante (1994). The pancreatic segment, besides pancreas, comprised liver, heart

179 muscle and spine. The intestinal segment contained the intestine, muscle and spine.

180 Dissection was conducted under a binocular on a glass plate cooled on ice.

181

182 Seventeen and 24-days-old larvae were not dissected due to their smaller size. These larvae

183 were homogenized with a Vortex mixer at maximum speed for $30 \mathrm{~s}$ and centrifuged at $2000 \mathrm{~g}$

184 ( 1 min and $4^{\circ} \mathrm{C}$ ) in order to tear up the larval abdomen and intestine. The supernatant was kept

185 and treated as the intestinal segments of dissected larvae. The pellet was homogenized in 500

$186 \mu \mathrm{l}$ cold distilled water and treated as pancreatic segments in dissected larvae.

187 Dissected samples (pancreatic and intestinal, 35 and $45 \mathrm{dph}$ ) were homogenized in $500 \mu \mathrm{l}$

188 cold distilled water using a homogenizer (Polytron, PT-MR 2100) at maximum speed for $30 \mathrm{~s}$.

189 The homogenate was centrifuged at $3300 \mathrm{~g}\left(3 \mathrm{~min}\right.$ and $\left.4^{\circ} \mathrm{C}\right)$ and the supernatant was collected.

190 Intestinal segments were homogenized to purify brush border membranes by the method of

191 intestinal scrapping (Crane et al., 1979) and modified for intestinal segments of fish larvae

192 (Cahu and Zambonino Infante, 1994). Before $\mathrm{CaCl}_{2}$ was added in the procedure, 50-100 $\mu$ l of

193 homogenate was removed for assays for total intestinal enzyme activity.

194 Due to the different procedures, larvae from 17 and 24 dph were not statistically compared

195 with larvae from 35 and 45 dph.

196

197 Trypsine activity was assayed according to Holm et al. (1988) and amylase activity was

198 assayed according to Métais and Bieth (1968) in both pancreatic and intestinal isolates.

199 Intestinal and pancreatic trypsine activity was determined using N $\alpha$-Benzoyl-DL-arginine-p- 
200

201

202

203

204

205

206

207

208

209

210

211

212

213

214

215

216

217

218

219

220

221

222

223

224

nitroanilide (Sigma B4875) as substrate ( $\mathrm{pH} \mathrm{7,} 25^{\circ} \mathrm{C}$ ). Amylase activity was determined using starch as substrate ( $\mathrm{pH} 7,30 \mathrm{~min}$ and $\left.37^{\circ} \mathrm{C}\right)$.

Alkaline phosphatase (AP) activity was assayed in intestinal homogenate and isolated brush border according to Bessey et al. (1946) using p-nitrophenylphosphate (Merck, 6850) as substrate (pH 7, 2 min and $\left.37^{\circ} \mathrm{C}\right)$.

Assays for leucine-alanine peptidase (leu-ala) activity were performed on intestinal segments for larvae according to the method of Nicholson et al. (1974). Leucine-p-nitroanilide (Sigma, L9125) was used as substrate ( $\mathrm{pH} \mathrm{7,2}$ min and $\left.37^{\circ} \mathrm{C}\right)$. Absorbance was read at $407 \mathrm{~nm}$ (trypsine, amylase, AP) and $410 \mathrm{~nm}$ (leu-ala) in a spectrophotometer (Unicom He $\lambda$ lios $\alpha$ ).

Larval protein content was determined by the method of Bradford (1976) and enzyme activity was expressed as specific activity being $\mu \mathrm{mol}$ of substrate hydrolysed per min per mg protein (U/mg protein).

\subsection{Spectrofluorometric determination of neutral lipase (n-lipase)}

Ten larvae were randomly sampled from all treatments on 35 and $45 \mathrm{dph}$. Larvae were dissected as described above. Samples were homogenized on ice in $600 \mu \mathrm{l}$ potassium phosphate buffer (50 mM, pH 7.8) by an ultra-turrax homogenizer (T8, IKA Labortechnik). After centrifugation at $3300 \mathrm{~g}\left(4 \mathrm{~min}\right.$ and $\left.4{ }^{\circ} \mathrm{C}\right)$, the supernatant was collected. Larval samples from each treatment were denatured at $80{ }^{\circ} \mathrm{C}$ for $1 \mathrm{~h}$ to inhibit any enzyme activity and thus were used as blanks.

$\mathrm{N}$-lipase activities were determined by the method of Roberts (1985) as described by Izquierdo and Henderson (1998) using 4-methylumbelliferyl heptanoate (4-MUH, Sigma, M2514) as substrate. The substrate was added as liposomes to the enzymatic reaction (pH 7.8, 15 min and $35^{\circ} \mathrm{C}$ ). The product of the hydrolysis was highly fluorescent and was quantified in 
a spectrofluorometer (Perkin Elmer LS 50 B) at an excitation setting of $365 \mathrm{~nm}$ and an emission setting of $450 \mathrm{~nm}$. Enzyme activity was calculated by using a standard curve based on 4-methylumbelliferone (4-MU) concentrations.

Sample protein in the samples for lipolytic activities was determined by a BioRad microassay kit based on the method of Bradford (1976) and enzyme activity was expressed as $\mu$ mol of substrate hydrolysed per min per mg protein (U/mg protein).

\subsection{Statistics}

Data were tested for homogeneity of variances using a Levene test. To compare means, the group data were statistically tested using one-way ANOVA followed by a Student-Newman-

Keuls-Test for more than two means. When variances were not homogenate; a non parametric Kruskal-Wallis test was accomplished. Two means were compared by a Student`s t-test. A 5 \% level of confidence was used throughout. All statistical analysis was performed using the software SPSS 14.0 for Windows.

\section{Results}

At the end of the rearing period, final dry weight was significantly higher in larvae fed the PL3 (2.67 $\pm 0.39 \mathrm{mg})$ and PL1 (2.75 $\pm 0.52 \mathrm{mg})$ diets than the NL1 (2.23 $\pm 0.16 \mathrm{mg})$ diet (Fig. 1). Dry weight increased from 0.1 to $0.4 \mathrm{mg}$ from hatching to 24 (dph) (Fig. 1). Between 24 and 45 dph larvae fed the PL3 and PL1 diets increased their dry weight nearly 7 folds while larvae fed the NL1 diet increased their dry weight 5.5 times. Growth in terms of daily weight increase (DWI) was reduced in all treatments during the first 11 days (24 to $35 \mathrm{dph}$ ) when larvae started to be fed dry feed only, compared to the co-feeding period (significant only in the PL3 treatment). Thereafter the DWI increased significantly in the PL3 and PL1 treatment 
during the last ten days of the experiment (35 to $45 \mathrm{dph}$, Table 2). When comparing different dietary treatments at equal time intervals there were no significant differences in DWI. Larval survival was not significantly affected by the different experimental diets (Fig. 2). At the end of the experiment the average survival was $12.2 \pm 0.5 \%$ for larvae fed the PL3 diet, $12.8 \pm 3.5 \%$ for PL1 and $15.7 \pm 4.5$ and for NL1-diet.

Activity of the brush border enzyme alkaline phosphatase (AP) was low in larvae on 17 and $24 \mathrm{dph}$. On $17 \mathrm{dph}$ the average activity was $29.1 \pm 6.7 \mathrm{mU} / \mathrm{mg}$ protein, and no significant alterations in AP activity were observed in larvae on 24 dph (Fig. 3A). AP activity increased strongly between 24 and 35 dph in all treatments, and on 45 dph activity of AP was significantly higher in the PL3 treatment (4227 $\pm 290 \mathrm{mU} / \mathrm{mg}$ protein) than in the PL1 (3310

$260 \pm 325 \mathrm{mU} / \mathrm{mg}$ protein) and NL1 (2625 $\pm 496 \mathrm{mU} / \mathrm{mg}$ protein) treatment (Fig. 3B).

The activity of the cytosolic peptidase leu-ala in larval homogenates increased significantly from17 dph to $24 \mathrm{dph}$ in all treatments (Fig. 3C). As for alkaline phosphatase a strong

264 increase in leu-ala activity was seen from 24 to $35 \mathrm{dph}$, while the activity decreased in all 265 treatments thereafter, being significantly lower in PL1 and NL1 treatment. On 45 dph 266 significantly higher leu-ala activity was apparent in PL3-larvae (1498 $\pm 76 \mathrm{U} / \mathrm{mg}$ protein) than in the PL1- (1175 \pm 96 U/mg protein) and NL1-larvae (1252 \pm 106 U/mg protein) larvae (Fig. 268 3D).

The ratio of the amount of AP in brush border membrane to the amount of leu-ala on 35 and 27145 dph (Table 3) showed a tendency towards higher values in larvae fed DHA and EPA in the 272 PL fraction of the diet. The ratio was significantly higher in larvae fed the PL3 diet on 35 dph 273 and in larvae fed the PL1 diet on 45 dph, being lowest in NL1-larvae on both days. 
275 Pancreatic activity of amylase decreased significantly in all treatments between 17 and 24 dph

276 (Fig. 4A), whereas a slight increase in intestinal activity was observed (Fig. 4B). The activity

277 was higher in the pancreatic segment than in the intestinal segment on 35 dph (Fig. 4C and

278 4D). Between 35 and 45 dph amylase activity decreased in the pancreatic segments, while it

279 was fairly stable in the intestinal segment. No significant differences in activity between

280 dietary treatments were evident during the experimental period.

281

282 The trypsin activity in the intestinal part was approximately one third of the activity in the 283 pancreatic part on $17 \mathrm{dph}$ (Fig. 5A and 5B). Between 17 and $24 \mathrm{dph}$, activity in pancreatic 284 segments decreased in all dietary treatments, being significantly lower in the PL3 and PL1 285 treatment. Simultaneously an increase in intestinal trypsin activity was observed. The 286 intestinal trypsin activity on 24 dph was not significantly different between treatments, while NL1-larvae had a significantly higher activity in the pancreatic segment on that day than the other treatments.

On 35 dph significant higher levels of trypsin activity in pancreatic segments were observed 290 in larvae fed the PL1 diet (Fig. 5C). Intestinal activity of trypsin was also higher in PL1larvae, although not significantly (Fig. 5D). On 45 dph intestinal trypsin activity was significantly higher in larvae fed the PL1 or the PL3-diet than the NL1 diet. The same tendency was seen for the pancreatic trypsin activity, although not significant.

Specific activity of neutral lipase (n-lipase) in the pancreatic segments of 35- and 45-days-old -larvae showed no differences between dietary treatments (Fig. 6A). However, the specific activity in intestinal segments showed significant differences between treatments on both days 
299 (Fig. 6B). On 35 dph the activity was higher in the PL3 treatment compared to the NL1

300 treatment, with PL1 being intermediate.

301 Between 35 and 45 dph the specific activity decreased significantly in the PL3 and PL1

302 treatment, being significantly higher in the NL1-treatment. On 45 dph the n-lipase pancreatic

303 activity was positively connected to the dietary level of triglycerides.

304

305

\section{Discussion}

306

307 In the present study DHA and EPA seemed to be more beneficial to larval growth and

308 development when incorporated in the polar lipid fraction (PL) than in the neutral lipid (NL)

309 fraction, as indicated by increased dry weight at the end of the experiment. NL1-larvae grew

310 slower than the PL3- and PL1-larvae, although they reached the exponential growth phase

311 during the experiment. The diets containing high and moderate levels of DHA and EPA in the

312 PL fraction (PL3 and PL1 respectively) induced the best growth and intestinal maturation as

313 indicated by the gut maturation index. In previous studies the relation between the amounts of

314 brush border enzymes and cytosolic enzymes have been used to express intestinal maturation

315 in sea bass, Senegal sole (Solea senegalesis) and yellow croacker larvae (Zambonino Infante

316 and Cahu, 1999 ; Buchet et al., 2000; Ribeiro et al., 2002; Ma et al., 2005). Higher values

317 correspond to a faster maturational process of enterocytes.

318 This might be caused by the levels and chemical location of DHA and EPA in the diet, since

319 the PL1 diet contained equal levels of DHA and EPA in the PL fraction as the NL1 diet

320 contained in the NL fraction. Cod larval ability to improve utilization of dietary PL compared

321 to NL was also reflected by a faster skeletal development of larvae fed the PL3 and PL1 diets

322 compared to those fed the NL1 diet (Kjørsvik et al., unpublished). Increased levels of marine

323 phospholipids have also resulted in better larval growth in larval European sea bass when 
324 weaned to formulated diets from mouth opening (Cahu et al., 2003a; Gisbert et al., 2005)

325 using the same dietary composition as in the present experiment. This is further supported by

326 findings of MacQueen Leifson et al. (2003) showing that marine phospholipids had a

327 beneficial effect on growth and enterocyte mitochondrial structures in larval turbot. Marine

328 fish larvae possess a high capacity to utilize dietary phospholipids (Salhi et al., 1999;

329 Izquierdo et al., 2001) and it has been shown for sea bass larvae that it is beneficial to

330 incorporate at least some of the dietary DHA/EPA content into the PL fraction (Cahu et al.,

331 2003a; Gisbert et al., 2005). The more efficient use of DHA and EPA supplied in the PL class

332 of the diet might be related to the ability of young larvae to better modulate phospholipase $\mathrm{A}_{2}$

333 expression than that of lipase, suggesting a more efficient capacity to assimilate PL than NL

334 as showed in sea bass larvae (Cahu et al., 2003a).

335 However, differences in growth were not associated to cod larval survival in this experiment.

336 This is in accordance with weaning experiments with sea bass larvae (Cahu and Zambonino

337 Infante, 1994; Morais et al., 2004), when there are sufficient essential nutrients available in

338 the formulated diets to keep up larval survival.

340 The differences in growth between the PL3 and PL1 diets and the NL1 diet between 35 and

$34145 \mathrm{dph}$ were reflected by the specific activity of the intestinal digestive enzymes. The specific

342 activity of AP remained low in whole larvae homogenates from 17 to $24 \mathrm{dph}$ and increased

343 thereafter, which may suggest an increase in cod larval digestive capacity. An increase in AP

344 activity generally occurs during larval and post larval development (Cahu and Zambonino

345 Infante, 1994; Ribeiro et al., 2002; Ma et al., 2005; Perez-Casanova et al., 2006). This

346 increase corresponds to the maturation process of enterocytes and the settlement of an

347 efficient digestion on the brush border level. 
348 In early larval stages, the enterocyte microvilli layer is poorly developed and the activity of

349 brush border membrane enzymes is low. During the development of larval cod in the present

350 study, the specific activity of AP increased in all treatments between 24 and $45 \mathrm{dph}$. This

351 increase in AP activity demonstrates the intestinal maturation and is supported by other

352 experiments with larval cod using live feed (O`Brien-MacDonald et al., 2006; Perez-

353 Casanova et al., 2006) and other marine species such as sea bass and yellow croaker

354 (Pseudosciaena crocea) (Cahu and Zambonino Infante, 1995; Ma et al., 2005). While AP

355 activity increased in both the PL3- (significantly) and PL1-treatment (not significantly) it did

356 not increase at all in the NL1 treatment between 35 and 45 dph, indicating a slower

357 maturation and pointing to the diet-dependent process as previously suggested in other studies

358 with cod and other marine fish species (Cahu and Zambonino Infante, 1995; Zambonino

359 Infante and Cahu, 1999; Ribeiro et al., 2002; O`Brien-MacDonald et al., 2006).

360 The lower activity is probably not caused by reduced larval growth due to an inadequate

361 dietary composition of the NL1 diet. A decrease in AP activity usually accompanies feeding

362 with inadequate diets (Gawlicka et. al., 1996) or starvation (Cousin et al., 1987). In the

363 present study the relation between amounts of AP and leu-ala was higher in larvae fed the

364 PL3 and PL1 treatments indicating a faster maturation of the intestine of these larvae than in 365 the NL1 treatment.

367 Leu-ala specific activity increased between 17 and 35 dph; which indicates that the cod larvae

368 increased their capacity of intracellular digestion. A decrease in specific activity in intestinal

369 segments of leu-ala between 35 and $45 \mathrm{dph}$, suggested a decrease in the intracellular digestion 370 during development as also reported in sea bass (Zambonino Infante and Cahu,1997; Cahu et 371 al., 2003a) and yellow croacker (Ma et al., 2005). The marked decrease with age of cytosolic

372 enzymes and the concurrent and abrupt increase in brush border enzymes characterize the 
normal maturation of the enterocytes in the developing animals (Henning, 1987), and this was observed in cod larvae between 35 and 45 dph in the present study.

With the exception on 24 dph, young cod larvae exhibited higher amylase activities in the pancreas than older larvae. The decrease in specific activity in pancreatic segments in cod larvae between 35 and 45 dph and the low activity in intestinal segments at the same age indicated a pancreatic development during the period. The amylase pattern in fish larvae may be compared with the decline of lactase expression observed during early development in mammals (Freund et al., 1990), and has previously been described in larval sea bass (Zambonino Infante and Cahu, 1994; Pères et al., 1996), walleye pollock (Theraga chalcogramma, Oozeki and Bailey, 1995), Solea senegalesis (Ribeiro et al., 1999) and yellow croacker (Ma et al., 2005). The higher amylase activities in younger larvae may express a predisposition of marine fish larvae to use carbohydrates during the early stages of life.

Generally, no clear differences in patterns of trypsin or amylase activity were observed between dietary treatments. This might be explained by the dietary compositions comprising comparable amounts of protein and starch in each of the diets. However, a significant higher trypsin activity was measured in pancreatic segments on 35 dph in larvae fed the PL1 diet. The same tendency was observed in intestinal segments. This might be explained due to higher ingestion rates of the PL1 diet, and thereby ingestion of a higher amount of protein. This assumption may also be supported by the tendency of PL1 larvae to possess higher daily weight increase values between 35 and $45 \mathrm{dph}$. Previous experiments have shown that trypsin activity is directly related to dietary protein content from 35 dph in sea bass larvae, whereas this regulatory process may not be functional in younger larvae (Pères, et al., 1996). Hjelmeland et al. (1988) showed that ingestion of inert polystyrene spheres induced higher 
398

399

400

401

402

403

404

405

levels of trypsin in pancreas and intestine of larval herring than in starved larvae. Experiments with sea bass and turbot larvae, using live feed, also indicated better growth with high food levels due to higher larval ingestion rates when diets had the same composition (Zambonino Infante et al., 1996; Hoehne-Reitan et al., 2001). Pedersen et al. (1990) observed that trypsin and trypsinogen contents depended on food supply in Clupea harengus larvae fed copepods. Lower ingestion rates might also be the explanation to decreased pancreatic activity of amylase and trypsin in pancreatic segments during co-feeding. Cod larvae preferably seem to ingest live prey instead of formulated diets when live prey is available (Baskerville-Bridges and Kling, 2000).

The specific activity of n-lipase in intestinal segments was affected by the different diets. On $45 \mathrm{dph}$ the lipase activity was 10 times higher in larvae fed the high NL levels (NL1) compared with low NL levels (PL3).

The activity of n-lipase showed high variability between dietary treatments on both 35 and 45 dph. On 45 dph there was a clear relation between enzyme activity and dietary lipid composition, suggesting that the mechanism of lipase regulation due to dietary composition in cod may be activated at the end of the larval phase. Lipase activity in cod larvae did not seem to be affected by the dietary lipid content in a comparable experiment during the first feeding phase (5 to 17 dph) (Hoehne, 1999) and turbot from 7 dph (Hoehne, 1999). However, lipase and PLA $\mathrm{A}_{2}$ activities were stimulated at the end of the larval phase in sea bass according to the increase in the respective dietary substrates triglycerides and phospholipids (formulated diets with 10-30\% lipid) (Zambonino Infante and Cahu, 1999).

Overall the activity of lipase, trypsin and AP was lower in the present study than reported in other studies with larval cod (O`Brien-MacDonald et al., 2006; Perez-Casanova et al., 2006). 
423 It is difficult to make precise comparisons between these studies due to different rearing

424 protocols, diets, sampling procedures and analytical methods. Lower enzyme activity in

425 larvae fed formulated diets have been reported by Hoehne-Reitan et al. (2003) who described

426 that the specific activity of neutral lipase in turbot larvae (13 dph) was affected by the diet,

427 observing higher activity in larvae fed live feed compared with larvae fed formulated diets. As

428 previously discussed this might be explained by differences in ingestion rates.

429 All diets used in the present study supported the growth and development of cod larvae, but

430 growth was lower than reported in comparable studies reported by Folkvord (2005) when

431 larvae were fed on live plankton. However, larval dry weight on 45 dph in the present study

432 (approximately 540 day degrees) was comparable with early weaned cod larvae on 50 dph

433 (approximately 530 day degrees) in studies described by Baskerville-Bridges and Kling

434 (2000). Larval dry weight on 30-35 dph was comparable with larvae fed live feed reported by

435 Galloway et al. (1999) and Hoehne (1999) under equal rearing conditions as the present study,

436 illustrating the potential of improving formulated diets and for early weaning of cod larvae.

438 Conclusion

439 In conclusion, rearing of cod larvae by substituting Artemia completely with a formulated diet

440 was successful. Larval growth and intestinal maturation suggested that the incorporation form

441 of DHA and EPA (PL or NL) in the diet may be crucial for cod larval development; being

442 more beneficial when DHA and EPA were present in the PL-fraction of the diets rather than

443 the NL-fraction. These results should be taken into account in the formulation of compound

444 diets for cod larvae. However, a more comprehensive gradient experiment is necessary to

445 evaluate the optimal lipid composition of an early weaning diet for this species. 
449

450

451

452

453

454

455

456

457

458

459

460

461

462

463

464

465

466

467

468

469

470

471

472

\section{0}

\section{Acknowledgements}

We thank the Norwegian Research Council for funding through the research projects

“CodTech” (NRC 153422/120) and "Effects of phospholipid supplement in microdiets during co-feeding of marine fish larvae” (NRC 142025/120).

The authors will also thank M. M. Le Gall at the IFREMER laboratory in Brest and T. Bardal at the department of biology (NTNU) for great help when performing the enzyme assays.

\section{References}

Baskerville-Bridges, B., Kling, L.J., 2000. Early weaning of Atlantic cod (Gadus morhua) larvae onto a microparticulate diet. Aquaculture 189, 109-117.

Bell, J. G., McEvoy, L. A., Estevez, A., Shields, R. J., Sargent, J. R., 2003. Optimising lipid nutrition in first-feeding flatfish larvae. Aquaculture 227, 203-220.

Bessey, O. A., Lowry, O. H., Brock, M. J., 1946. Rapid coloric method for determination of alkaline phosphatase in five cubic millimetres of serum. J. Biol. Chem. 164, 321-329.

Bradford, M. M., 1976. A rapid and sensitive method for the quantitation of microgram quantities of protein utilizing the principle of protein-dye binding. Anal. Biochem. 72, 248254.

71 Buchet, V., Zambonino Infante, J. L., Cahu, C. L., 2000. Effect on lipid level in a compound diet on the development of red drum (Sciaenops ocellatus) larvae. Aquaculture 184, 339-347. 
474 Cahu, C. L., Zambonino Infante, J. L., 1994. Early weaning of sea bass (Dicentrarchus labrax)

475 larvae with a compound diet: effect on digestive enzymes. Comp. Biochem. Physiol 109A, $476 \quad 213-222$.

477

478 Cahu, C. L., Zambonino Infante, J. L., 1995. Effect of molecular form of dietary nitrogen 479 supply in sea bass larvae: response of pancreatic enzymes and intestinal peptidases. Fish 480 Physiol. Biochem. 14, 209-214.

481

Cahu, C., Zambonino Infante, J., 2001. Substitution of live food by formulated diets in marine 483 fish larvae. Aquaculture 200, 162-180.

484

485

Cahu, C. L., Zambonino Infante, J. L., Barbosa, V., 2003a. Effect of dietary phospholipid 486 level and phospholipid: neutral lipid value on the development of sea bass (Dicentrarchus labrax) larvae fed a compound diet. Br. J. Nutr. 90, 21-28.

488

489 Cahu, C. L., Zambonino Infante, J. L., Takeuchi, T., V., 2003b. Nutritional components 490 affecting skeletal development in fish larvae. Aquaculture 227, 245-258.

491

Cousin, J. B., Baudin-Laurencin, F., Gabaudan, J., 1987. Ontogeny of enzymatic activities in 493 fed and fasting turbot, Scophthalmus maximus L. J. Fish Biol. 30, 15-33.

494

495 Crane, R. K., Boge, G., Rigal, A., 1979. Isolation of brush border membranes in vesicular 496 form from intestinal spiral valve of the small dogfish (Scyliorhinus canicula). Biochim. 497 Biophys. Acta 554, 264-267. 
499 Folkvord, A. 2005. Comparison of size-at-age of larval Atlantic cod (Gadus morhua) from

500 different populations based on size- and temperature-dependent growth models. Can. J. Fish. 501 Aqua. Sci. 62, 1037-1052.

502

503 Freund, J.N., Torp, N., Duluc, I., Foltzer-Jourdaine, C., Danielsen, M., Raul, F., 1990.

504 Comparative expression of mRNA for three intestinal hydrolases during post-natal 505 development in the rat. Cell. Mol. Biol. 36, 729-736.

506

507 Galloway, T. F., Kjørsvik, E., Kryvi, H., 1999. Muscle growth and development in Atlantic

508 cod larvae (Gadus morhua L.) related to different somatic growth rates. J. Exp. Biol. 202, $509 \quad 2111-2120$.

510

511 Gawlicka, A., McLaughlin, L., Hung, S.S.O., de la Noüe, J., 1996. Limitations of carrageenan

512 microbound diets for feeding white sturgeon, Acipenser transmontanus, larvae. Aquaculture 513 141, 245-265.

514

515 Gisbert, E., Villeneuve, L., Zambonino Infante, J. L., Quazuguel, P., Cahu, C. L., 2005.

516 Dietary phospholipids are more efficient than neutral lipids for long-chain polyunsaturated

517 fatty acid supply in European sea bass Dicentrarchus labrax larval development. Lipids 40(6), $518 \quad 1-11$.

520 Geurden, I., Bergot, P., Schwarz, L., Sorgeloos, P. 1998. Relationship between dietary 521 phospholipid classes and neural lipid absorption in newly-weaned turbot, Scophthalmus

522 maximus. Fish Physiol. Biochem. 19 (3), 217-228. 
524 Gomez, A, Serra, M., Carvalho, G. R., Lunt, D. H. 2002. Speciation in ancient cryptic species complexes: evidence from the molecular phylogeny of Brachionus plicatilis (Rotifera). Evolution 56 (7), 1431-1444.

Hamre, K. 2006. Nutrition in cod (Gadus morhua) larvae and juveniles. ICES J. Mar. Sci. 63, 267-274.

530

Henning, S. J. 1987. Functional development of the gastrointestinal tract. In: Johnson, L. R. (Ed.), Physiology of Gastrointestinal Tract. Raven Press, New York, pp. 571-610.

Hjelmeland, K., Pedersen, B. H., Nilssen, E. M., 1988. Trypsin content in intestines of herring larvae, Clupea harengus, ingesting inert polystyrene spheres or live crustacean prey. Mar. Biol. 98, 331-335.

Hoehne, K. 1999. Lipid digestive enzymes in developing larvae of the Atlantic cod (Gadus morhua) and turbot (Scophthalmus maximus). $\mathrm{PhD}$ thesis, University of Karlsruhe/Norwegian University of Science and Technology. Shaker Verlag. 111pp. dependent lipase in larval turbot. J. Fish Biol. 58, 737-745.

545 Hoehne-Reitan, K., Kjørsvik, E., Reitan, K. I., 2003. Lipolytic activities in developing turbot 546 larvae as influenced by diet. Aquac. Int. 11, 477-489. 
548 Hoehne-Reitan, K., Kjørsvik, E., 2004. Functional development of the liver and exocrine 549 pancreas in teleost fish. Am. Fish. Soc. Symp. 40, 9-36.

550

Holm, H., Hanssen, L. E., Krogdahl, A., Florholmen, J., 1988. High and low inhibitor

soybean meals affect human duodenal proteinase activity differently: in vivo comparison with

553 bovine serum albumin. J. Nutr. 118, 515-520.

554

555

Izquierdo, M. S. 2004. Nutritional requirements for finfish larvae. The Second Hatchery,

Feeds and Technology Workshop, 30 september-1 October 2004, Sidney, Australia, pp. 8-16.

Izquierdo, M.S, Henderson, R. J., 1998. The determination of lipase and phospholipase

activities in gut contents of turbot (Scophthalmus maximus) by fluorescence-based assays.

Fish Physiol. Biochem. 19, 153-162.

561

Izquierdo, M.S., Tandler, A., Salhi, M., Kolkovski, S., 2001. Influence of dietary polar

563 lipids `quantity and quality on ingestion and assimilation of labelled fatty acids by larval

564 gilthead sea bream. Aquac. Nutr. 7, 153-160.

565

Kjørsvik, E., Pittman, K., Pavlov, D., 2004. From fertilisation to the end of metamorphosis-

567 functional development. First feeding technology. In "Culture of cold-water marine fish.

568 Moksness, E., Kjørsvik, E. and Olsen, Y. (eds). Blackwell Publishing Ltd. pp. 204-278.

570 Ma, H., Cahu, C., Zambonino, J., Yu, H., Duan, Q., Le Gall, M. M., Mai, K., 2005. Activities

571 of selected digestive enzymes during larval development of large yellow croaker

572 (Pseudosciaena crocea). Aquaculture 245, 239-248. 
574 MacQueen Leifson, R., 2003. Phospholipids in formulated starter feed for turbot

575 (Scophthalmus maximus) and cod (Gadus morhua L.) larvae- effects on mitochondrial

576 membranes in turbot larvae enterocytes. PhD thesis. University of Tromsø, Tromsø, Norway.

577

578 MacQueen Leifson, R., Homme, J. M., Lie, Ø., Myklebust, R., Strøm, T., 2003. Three

579 different lipid sources in formulated start-feeds for turbot (Scophthalmus maximus, L.) larvae-

580 effect on growth and mitochondrial alteration in enterocytes. Aquac. Nutr. 9, 33-42.

581

582

583

584

585

586

587

588

589

590

591

592

593 O`Brien-MacDonald, K., Brown, J., Parrish, C.C., 2006. Growth, behaviour, and digestive 594 enzyme activity in larval Atlantic cod (Gadus morhua) in relation to rotifer lipid. ICES J.

595 Mar. Sci. 63, 275-284.

Mètais, P., Bieth, J. 1968. Dètermination de l` $\alpha$-amylase par une microtechnique. Ann. Biol. Clin. 26, 133-142.

Morais, S., Cahu, C, C., Zambonino Infante, J. L., Robin, J., Rønnestad, I., Dinis, M. T., Conceição, L. E. C. 2004. Dietary TAG source and level affect performance and lipase expression in larval sea bass (Dicentrarchus labrax). Lipids 39(5), 449-458.

Nicholson, J. A., McCarthy, D. M., Kim, Y. S. 1974. The response of rat intestinal brush border and cytosol peptide hydrolase activites to variation of dietary protein content. J. Clin. Invest. 54:890-898.

596 
597

598

599

600

601

602

603

604

605

606

607

608

609

610

611

612

613

614

615

616

617

618

619

620

621

Olsen, Y., van der Meeren, T., Reitan, K. I., 2004. First feeding technology. In ”Culture of cold-water marine fish. Moksness, E., Kjørsvik, E. and Olsen, Y. (eds). Blackwell Publishing Ltd. pp. 279-336.

Oozeki, Y., Bailey, K. M., 1995. Ontogenetic development of digestive enzyme activities in larval walleye Pollock, Theragra chalcogramma. Mar. Biol. 122,177-186.

Pedersen, B. H., Uglestad, I., Hjelmeland, K., 1990. Effects of a transitory, low food supply in the early life of larval herring (Clupea harengus) on mortality, growth and digestive capacity. Mar. Biol. 107, 61-66.

Pères, A., Cahu, C. L., Zambonino Infante, J. L., Le Gall, M. M., Quazuguel, P., 1996. Amylase and trypsin responses to intake of dieatry carbohydrate and protein depend on the developmental stage in sea bass (Dicentrarchus labrax) larvae. Fish Physiol. Biochem. 15, 237-242.

Perez-Casanova, J. C., Murray, H. M., Gallant, J. W., Ross, N. W., Douglas, S. E., Johnson, S. C., 2006. Development of digestive capacity in larvae of haddock (Melanogrammus aeglefinus) and Atlantic cod (Gadus morhua). Aquaculture 251, 377-401.

Rainuzzo, J., Reitan, K. I., Olsen, Y., 1997. The significance of lipids at early stages of marine fish: a review. Aquaculture 155, 103-115.

Ribeiro, L., Zambonino Infante, J. L., Cahu, C., Dinis, M. T. 1999. Development of digestive enzymes in larvae of Solea senegalesis, Kaup 1858. Aquaculture 179, 465-473. 
623 Ribeiro, L., Zambonino Infante. J. L., Cahu, C. L., Dinis, M. T., 2002. Digestive enzymes

624 profile of Solea senegalesis post larvae fed Artemia and a compound diet. Fish Physiol.

625 Biochem. 27 (1-2), 61-69.

626

627 Roberts, I. M. 1985. Hydrolysis of 4-methylumbelliferyl butyrate: A convenient and sensitive 628 fluorescence assay for lipase activity. Lipids 20(4), 243-247.

629

630 Salhi, M., Hernàndez_Cruz, C. M., Bessonart, M., Izquerido, M. S., Fernàndez-Palacios, H., 631 1999. Effect of different dietary polar lipid levels and different n-3 HUFA content in polar 632 lipids on gut and liver histological structure of gilthead seabream (Sparus aurata) larvae. 633 Aquaculture 179, 253-263.

634

635 Salvesen, I., Vadstein, O., 1995. Surface disinfection of eggs from marine fish: evaluation of 636 four chemicals. Aquac. Int. 3, 155-171.

637

638 Sargent, J. R., Tocher, D. R., Bell, J. G. 2002. The lipids. In: Fish Nutrition. Halver, J. E and 639 Hardy, R. W. (eds). Academic Press. pp. 182-257.

640

641 Zambonino Infante, J. L., Cahu, C. L., 1994. Influence of diet on pepsin and some pancreatic 642 enzymes in sea bass (Dicentrarchus labrax) larval development. Comp. Biochem. Physiol. 643 109, 209-212. 
645 Zambonino Infante, J. L., Cahu, C. L., 1997. Partial substitution of di- and tripeptides for

646 native proteins in sea bass diet improves dicentrarchus labrax larval development. J. Nutr.

$647127(4), 608-614$.

648

649 Zambonino Infante, J. L., Cahu, C. L., 1999. High dietary lipid levels enhance digestive tract 650 maturation and improve Dicentrarchus labrax larval development. J. Nutr. 129 (6), 1195-

6511200.

652

653 Zambonino Infante J. L., Cahu, C. L., 2001. Ontogeny of the gastrointestinal tract of marine

654 fish larvae. Comp. Biochem. Physiol 130, 477-487.

655

656 Zambonino Infante, J. L., Cahu, C. L., Peres, A., Quazuguel, P., Le Gall, M. M., 1996. Sea

657 bass (Dicentrarchus labrax) larvae fed different Artemia rations: growth, pancreas enzymatic

658 response and development of digestive functions. Aquaculture 139, 129-138.

659

660

661

662

663

664

665

666

667

668

669 
670

671 Legends.

672

673

674

675

676

677

678

679

680

681

682

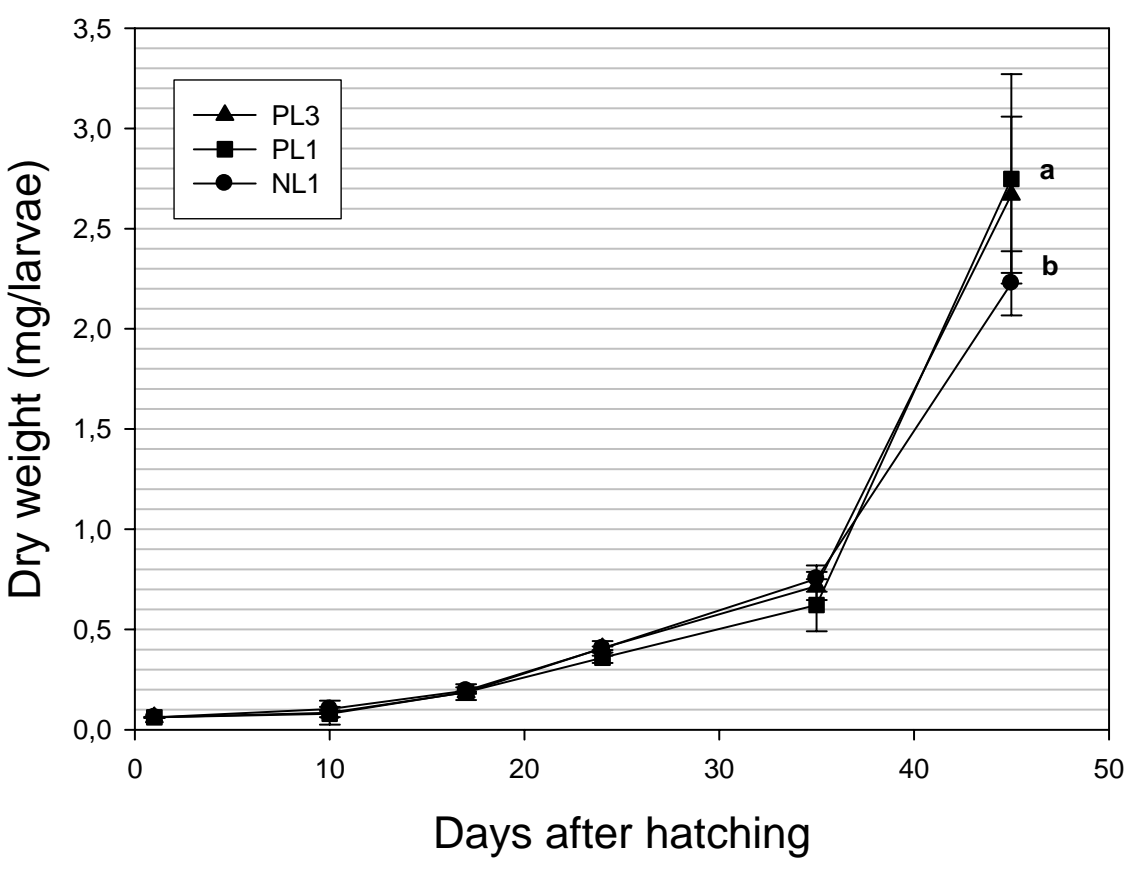

683

684 Fig. 1. Dry weight (mg DW/larvae) of cod larvae during the experiment (mean \pm s. e.

$685 \mathrm{n}=45-67)$. Different letters denote significant differences between dietary treatments.

686

687

688

689

690

691

692

693

694 


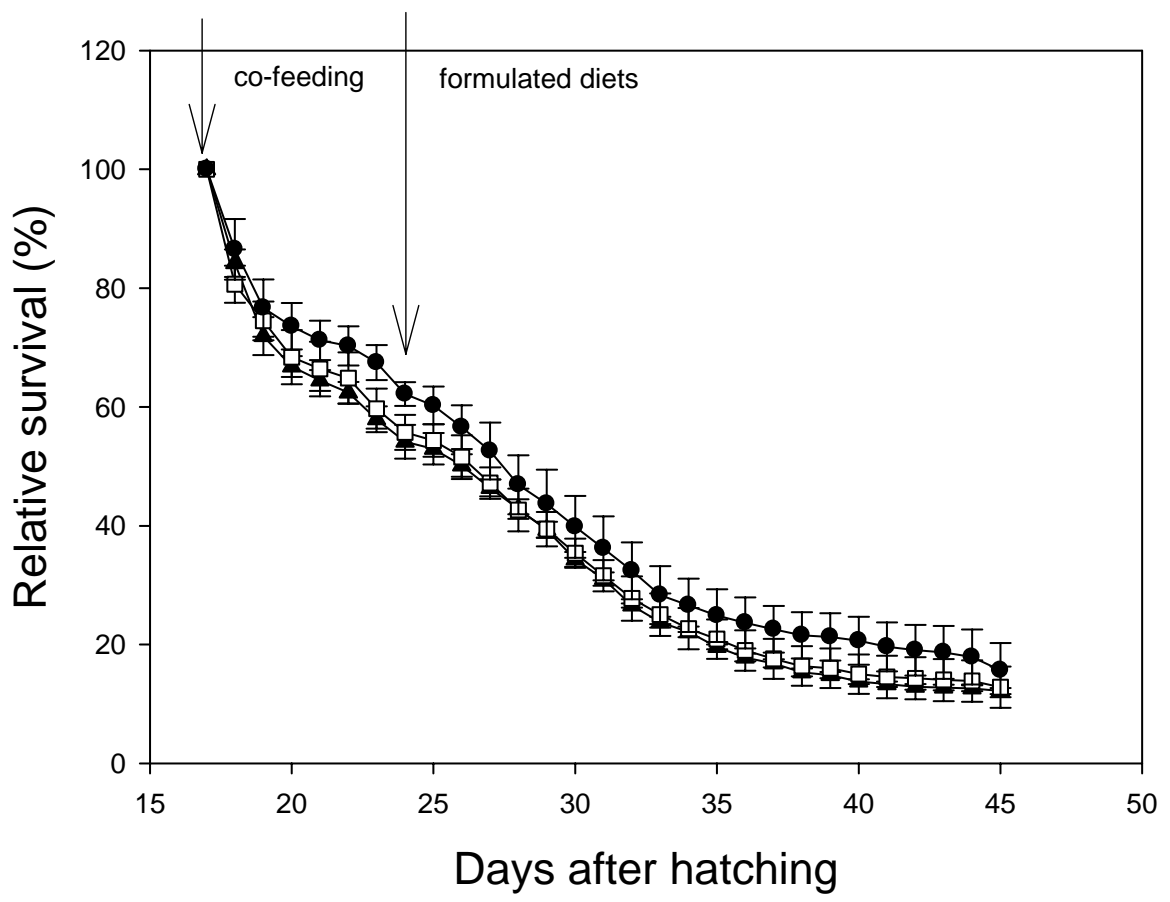

696 Fig. 2. Relative survival (in \%) of cod larvae (mean \pm s.e. $n=3$ ) during the periods of co697 feeding and feeding with formulated diets exclusively.

698

699 

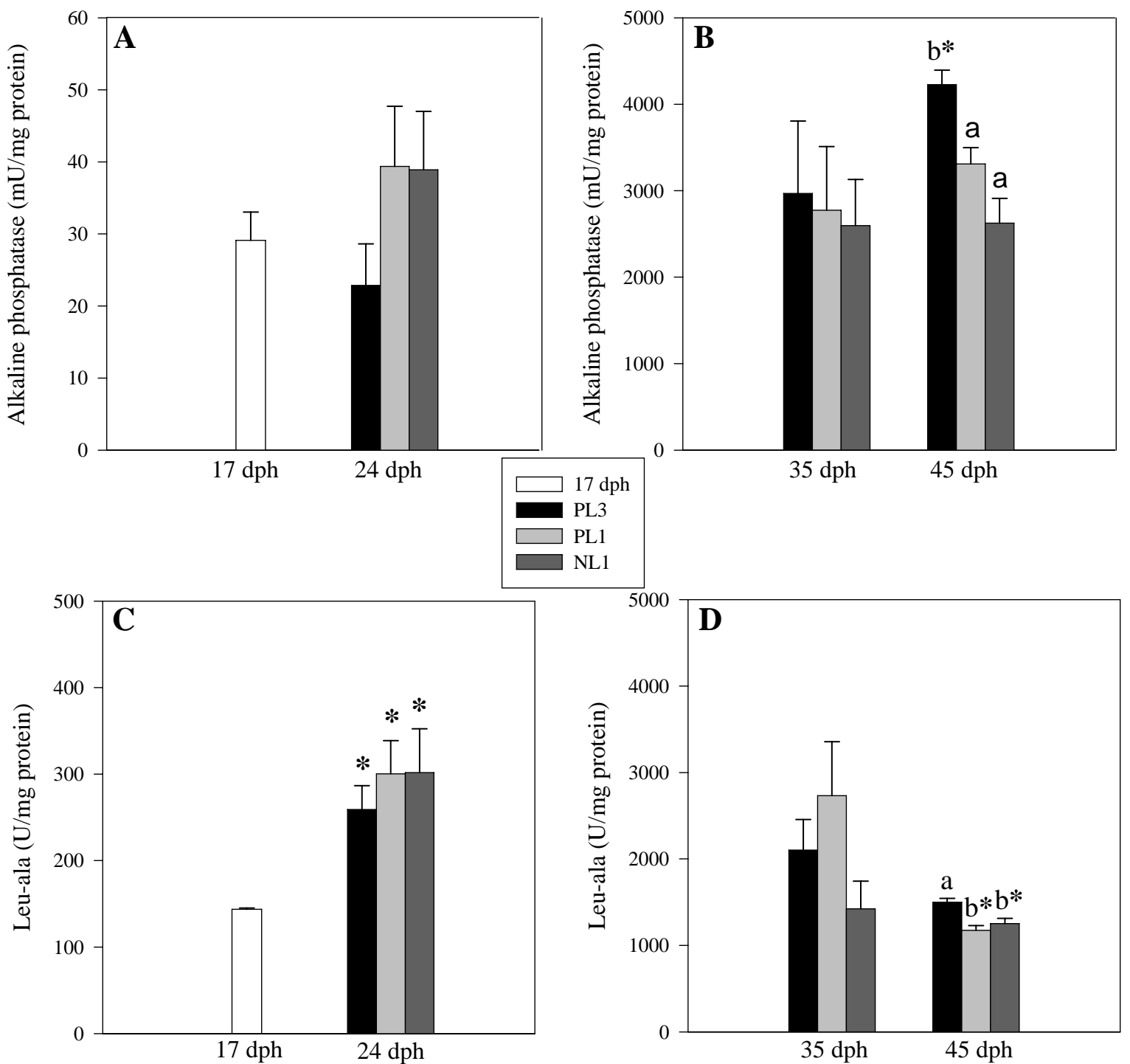

Fig. 3: A. Specific activity of alkaline phosphatase (mU/mg protein) in whole cod larvae on

17 and 24 dph. B. Specific activity of alkaline phosphatase (mU/mg protein) in the isolated

aminopeptidase (U/mg protein) in whole larvae on17 and $24 \mathrm{dph}$.

D. Specific activity of leuala in intestinal segments of dissected larvae 35 and 45 dph. $n=3$. Means \pm s.e.; $n=3$.

Different letters denote significant differences between treatments. Stars denote significant differences between different days for the same treatment (in the same graph). 

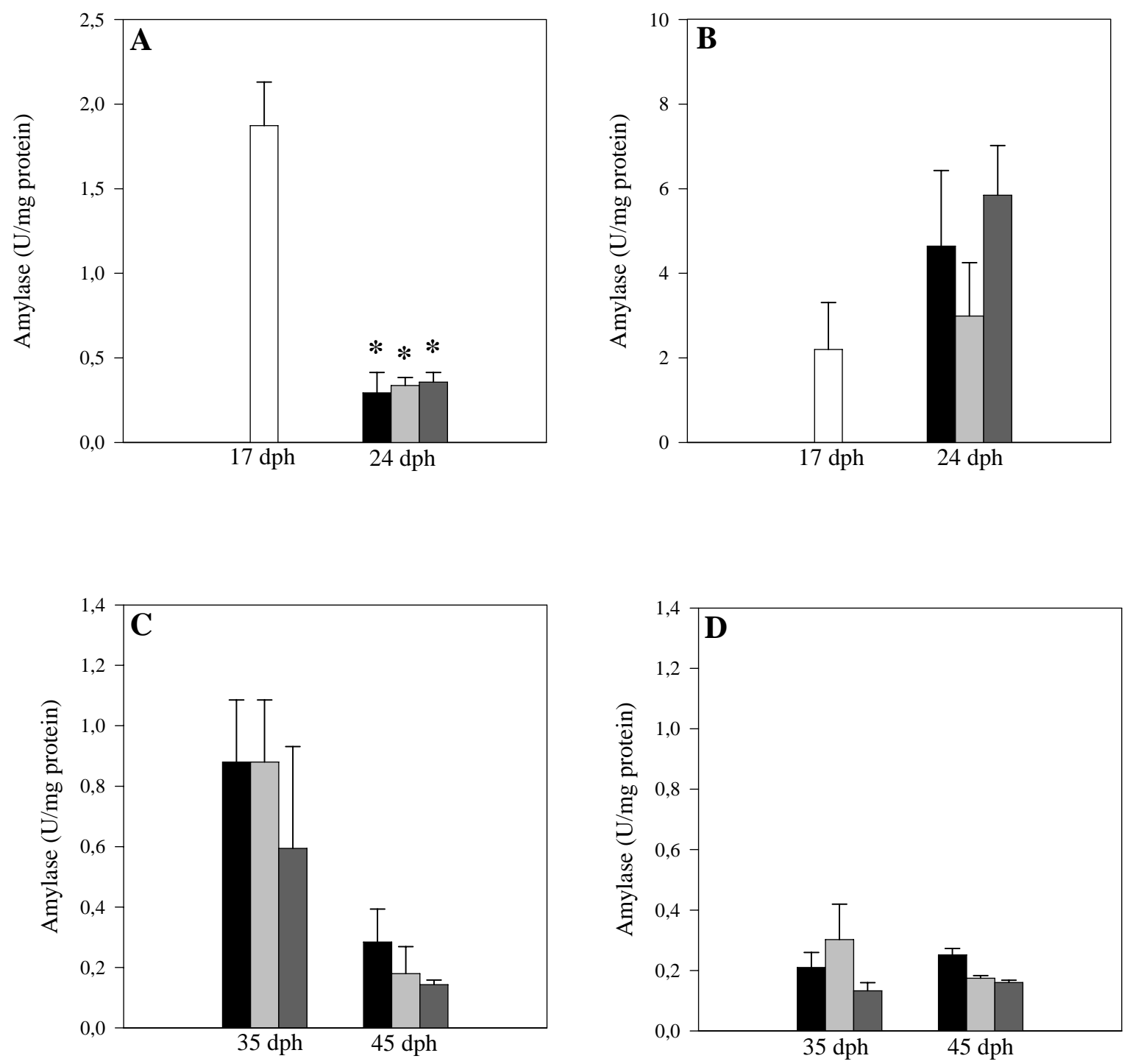

712 Fig. 4: Specific activity of $\alpha$-amylase (U/mg protein) in cod larvae A. In the pancreas of

713 larvae on 17 and $24 \mathrm{dph}$. B. In the intestine of larvae on 17 and $24 \mathrm{dph}$. C. In the pancreatic

714 segment of larvae on 35 and $45 \mathrm{dph}$. D. In the intestinal segment of larvae on 35 and $45 \mathrm{dph}$.

$715 \mathrm{n}=3$ (tanks). Means \pm s.e. Different letters denote significant differences between treatments.

716 Stars denote significant differences between days for the same treatment in the same graph. 

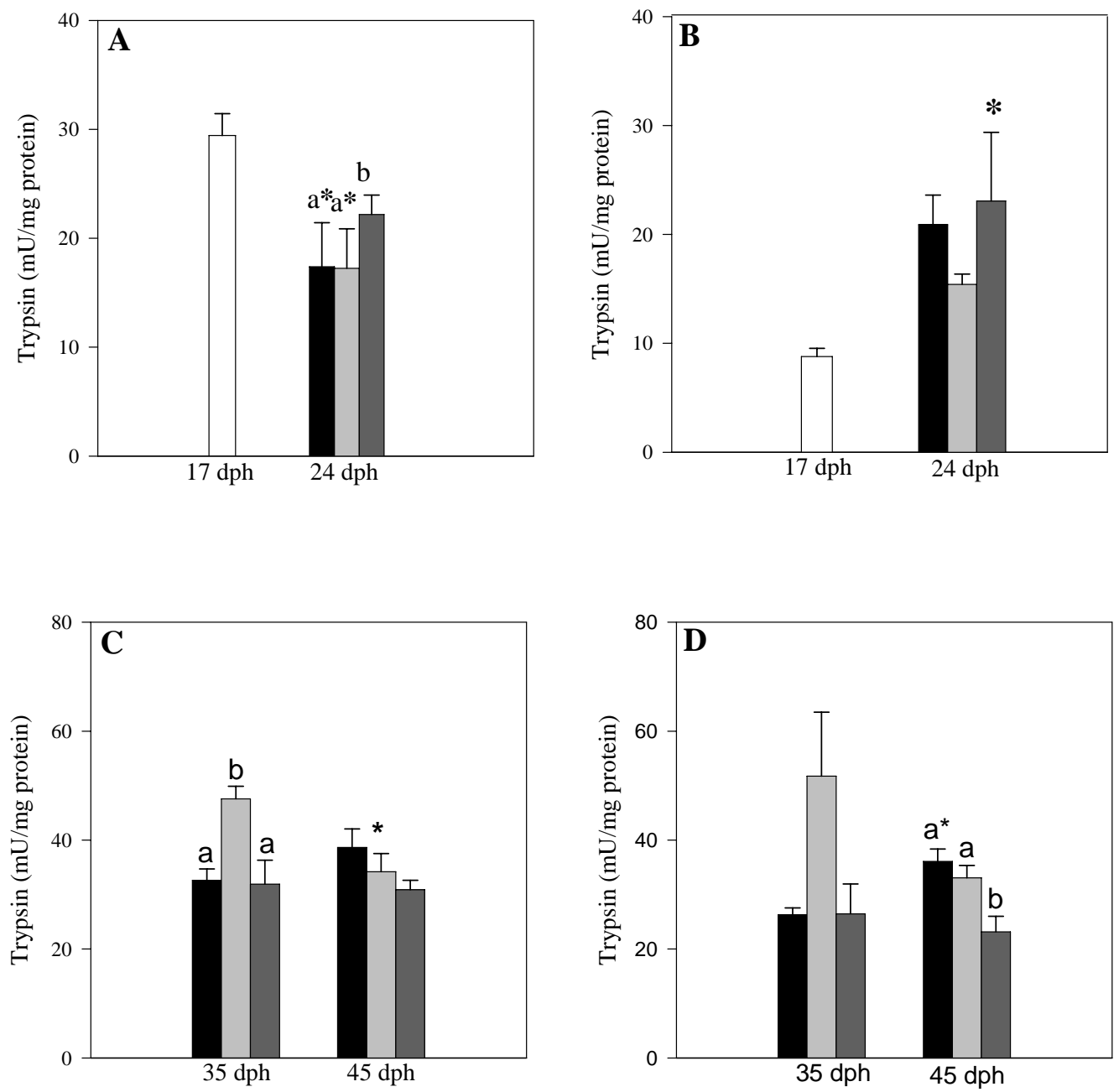

723 Fig. 5: Specific activity of trypsin (mU/mg protein) in cod larvae A. In the pancreas of larvae on 17 and 24 dph. B. In the intestine segment of larvae on 17 and 24 dph. C. In the pancreatic 725 segment of larvae 35 and $45 \mathrm{dph}$. D. In the intestinal segment of larvae on 35 and $45 \mathrm{dph}$. n=3 726 (tanks). Means \pm s.e. Different letters denote significant differences between treatments. Stars 727 denote significant differences between days for the same treatment (in the same graph). 


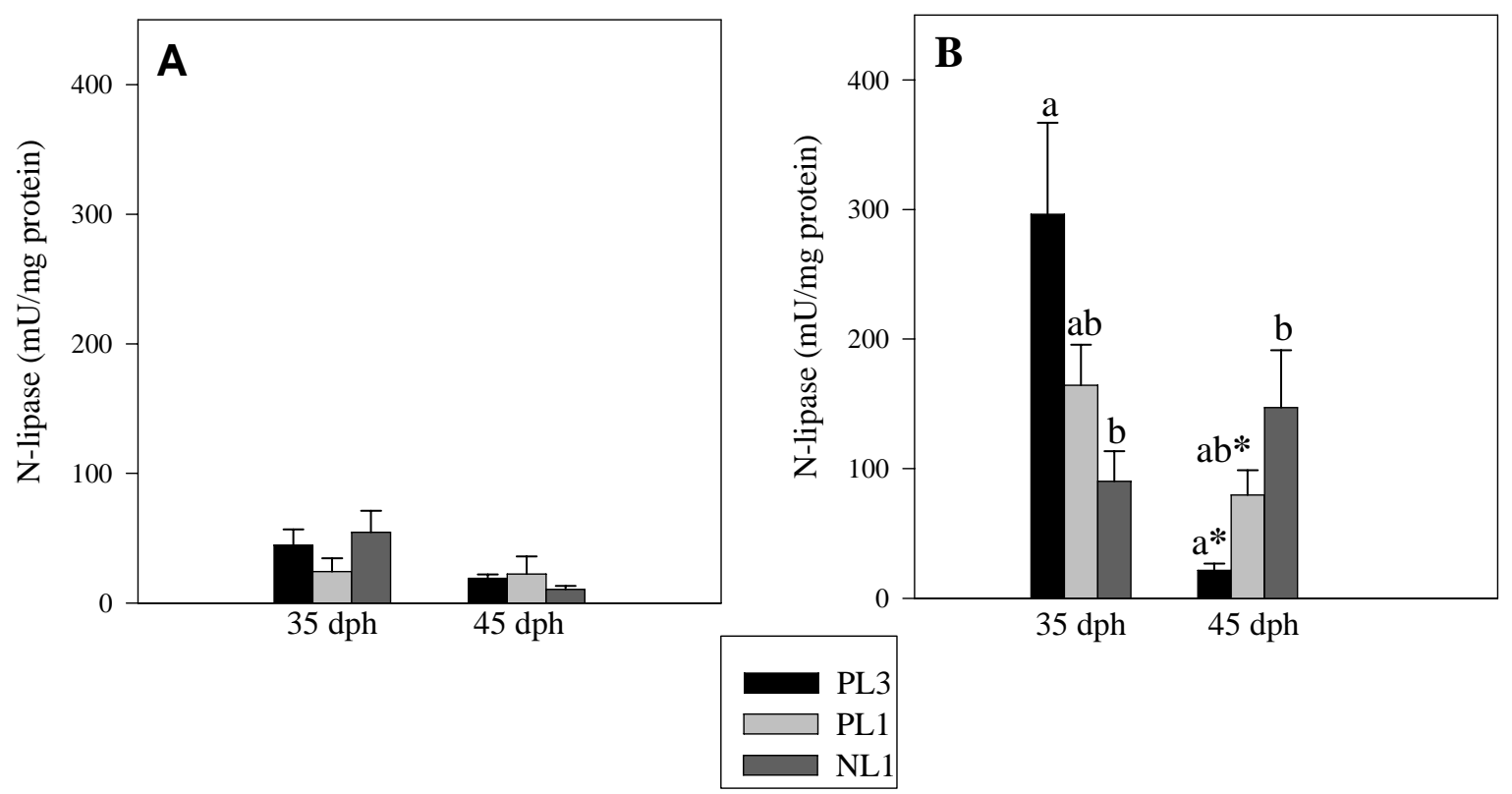

733 Fig. 6: Specific activity of neutral lipase in cod larvae (mU/mg protein) in pancreatic (A) and

734 intestinal parts $(\mathbf{B})$ of dissected cod larvae. $n=6-10$. Means \pm s.e. Different letters denote

735 significant differences between treatments. 
Table 1

Composition of experimental diets (\%).

\begin{tabular}{|c|c|c|c|}
\hline $\begin{array}{l}\text { Diet } \\
\text { Ingredients }^{\mathrm{a}}\end{array}$ & PL3 & PL1 & NL1 \\
\hline$\underline{\text { Lipid ingredients (g/100g) }}$ & & & \\
\hline Cod liver oil & 0 & 0 & 7 \\
\hline Marine lecithin ${ }^{\mathrm{b}}$ & 14 & 7 & 0 \\
\hline Soybean lecithin ${ }^{c}$ & 7 & 14 & 14 \\
\hline Proximate composition (\%) & & & \\
\hline Proteins ( $\mathrm{N}$ x 6.25) & 61.5 & 58.3 & 57.7 \\
\hline Lipids & 16.1 & 16.4 & 17.9 \\
\hline Phospholipids & 12.5 & 12.4 & 10.7 \\
\hline EPA + DHA in PL & 2.3 & 1.1 & 0.3 \\
\hline Neutral lipids & 3.7 & 4.4 & 6.8 \\
\hline EPA + DHA in NL & 0.3 & 0.3 & 1.3 \\
\hline Ash & 17.4 & 17.5 & 17.4 \\
\hline Moisture & 7.5 & 7.1 & 7.2 \\
\hline Energy $^{\mathrm{d}}$ & 1634 & 1592 & 1639 \\
\hline
\end{tabular}

${ }^{a}$ All dietary ingredients were commercially available. Fish meal (La Lorientaise, Lorient, 758 France), hydrolyzed fish meal (CPSP, Soluble Fish Protein Concentrate; Sopropêche, 759 Boulogne sur Mer, France), cod liver oil (La Lorientaise), marine lecithin (LC60, 760 Phosphomins $^{\mathrm{TM}}$; 
Phosphotech, Saint Herblain, France).

${ }^{\mathrm{b} C}$ Contains 60\% phospholipids (with 45\% PC, 20\% PE, 16\% PI), 5\% TAG, 15\% cholesterol, and $1 \mathrm{mg} / \mathrm{g}$ natural tocopherols as antioxidant.

${ }^{\mathrm{c} C}$ Contains 95\% phospholipids (with 26\% PC, 20\% PE, and 14\% PI).

${ }^{\mathrm{d} C}$ Calculated as: fat x $37.7 \mathrm{~J} / \mathrm{kg}$; protein x $16.7 \mathrm{~J} / \mathrm{kg}$.

\section{Table 2}

Daily weight increase (DWI) $(\%$, means \pm s.e.: $\mathrm{n}=3)$ during different time intervals.

Different letters denote significant differences in growth during different time intervals in the same dietary treatment.

\section{PL3 \\ PL1 \\ NL1}

Daily weight increase $(\% \pm$ s.e.)

17-24 dph (co-feeding)

$11.8 \pm 0.4^{\mathrm{a}}$

$9.8 \pm 1.7^{\mathrm{a}}$

$11.1 \pm 1.7^{\mathrm{a}}$

24-35 dph (form. diets)

$5.2 \pm 1.0^{b}$

$5.1 \pm 1.2^{\mathrm{a}}$

$5.8 \pm 1.6^{\mathrm{a}}$

35-45 dph (form. diets)

$13.3 \pm 2.2^{\mathrm{a}}$

$16.2 \pm 2.1^{\mathrm{b}}$

$11.4 \pm 0.6^{\mathrm{a}}$

\section{Table 3}

Ratio of segmental activity of alkaline phosphatase in the brush border membrane related to segmental activity of the cytosolic enzyme leu-ala peptidase (x 1000). Means \pm s.e. $(n=3)$. Different letters denote significant differences in the same row.

\begin{tabular}{l|ccc}
\hline & PL3 & PL1 & NL1 \\
\hline $35 \mathrm{dph}$ & $46.6 \pm 3.02^{\mathrm{a}}$ & $36.5 \pm 11.69^{\mathrm{b}}$ & $18.2 \pm 4.17^{\mathrm{b}}$ \\
& & & \\
\hline $45 \mathrm{dph}$ & $76.5 \pm 10.69^{\mathrm{b}}$ & $114.6 \pm 14.12^{\mathrm{a}}$ & $57.5 \pm 15.71^{\mathrm{b}}$
\end{tabular}

